\title{
Effects of colchicine on anther and microspore culture of bread wheat (Triticum aestivum L.)
}

\author{
Mercedes Soriano, Luis Cistué, María Pilar Vallés and Ana María Castillo \\ Departamento de Genética y Producción Vegetal, Estación Experimental de Aula Dei, \\ Consejo Superior de Investigaciones Científicas (CSIC), Avda Montañana 1005, \\ Zaragoza, 50059, Spain
}

$\checkmark$ Ana M. Castillo

Email: amcast@eead.csic.es 


\section{ABSTRACT}

The aim of this work was to study the effects of colchicine application on chromosome doubling and androgenic response in anther and microspore culture of different bread wheat genotypes. Colchicine was applied during a mannitol stress pretreatment or during the first $48 \mathrm{~h}$ of culture at concentrations of 0,150 and $300 \mathrm{mg}^{-1}$. When colchicine was applied during stress pretreatment, the percentage of doubling depended on genotype and concentration. A significant increase in doubling was observed with $300 \mathrm{mg}^{-1}$ in the low androgenic responding cv. Caramba. Colchicine incorporation during the first hours of culture improved percentage of doubling in all genotypes, in both anther and microspore culture. Application of $300 \mathrm{mg}^{-1}$ colchicine improved the percentage of doubling in the two low responding genotypes, to $118 \%$ of control in DH24033, and 75\% in Caramba in microspore and anther culture, respectively. Concerning the androgenic response, the effect of colchicine on embryo formation and percentage of green plants depended on the genotype and on the culture method. In cv. Pavon, a 2- and a 3-fold increase in percentage of embryogenesis and green plants, respectively, were obtained with $300 \mathrm{mg} \mathrm{l}^{-1}$ colchicine in microspore culture. However, no significant differences in these two variables were observed in anther culture. The number of green doubled haploid (DH) plants reflects the index of success of the procedure. Regardless of the culture method, when colchicine was incorporated during the first hours of culture, the number of green DH plants increased significantly in three of four genotypes. These results confirm the usefulness of colchicine application during the first hours of culture in wheat breeding programs.

Keywords Doubled haploid - Chromosome doubling - Androgenesis - Poaceae - Stress pretreatment 


\section{INTRODUCTION}

Doubled haploid (DH) plants are useful in plant breeding programmes, since homozygous plants may be obtained in a few months, thus reducing the time needed to release new cultivars. Several bread wheat cultivars selected from DH lines, obtained by microspore embryogenesis (Ouyang et al. 1983) or intersepecific crosses with maize (Laurie and Bennett 1987), have been commercialized (http://www.scri.sari.ac.uk/assoc/COST851/Default.htm). Microspore embryogenesis has greater potential for DH production than interspecific crosses in wheat, due to the abundance of microspores per flower compared to the single ovule per floret. However, there are still several factors that hinder the application of anther and microspore culture at a commercial level, specifically the low rates of embryogenesis and regeneration, the high frequency of albinism among regenerants and the low frequency of chromosome doubling in some cultivars.

The spontaneous doubling rate in wheat depends on the genotype. Stober and Hess (1997) obtained 15-44\% spontaneous doubling in German cultivars of spring wheat, whereas Barnabás (2003) reported frequencies from 25 to $68 \%$ in winter cultivars from Central and Eastern Europe. Of the different chromosome doubling agents, colchicine has been the most successful when applied to plants or callus of bread wheat (Hassawi and Liang 1991). Colchicine inhibits spindle formation during mitosis and disturbs normal polar segregation of sister chromatids resulting in doubling chromosome number (Levan 1938). Colchicine is traditionally applied to young plants at the $3-$ 4 tillering stage by the capping technique (inverted vial) (Bell 1950) or by the immersion method (Jensen 1974). However, the application of colchicine at this stage has several disadvantages such as: (a) the high concentration and volume of colchicine solution needed, that implies dangerous handling and costly treatments, (b) a high rate of mortality in plants, and (c) production of mixoploids or chimeric plants that leads to low seed production and therefore, an additional growth cycle for seed multiplication before evaluation in the field (Chen et al. 1994). The application of colchicine during in vitro culture, in the induction medium (Barnabás et al. 1991) or in the regeneration medium (Mentewab and Sarrafi 1997) could minimize some of these problems. 
Colchicine has been successfully applied during the first hours of anther and microspore culture, resulting in an increase of chromosome doubling in different species such as wheat (Barnabás et al. 1991, Hansen and Andersen 1998), tritordeum (Barcelo et al. 1994), maize (Saisingtong et al. 1996), rice (Alemanno and Guiderdoni 1994), Miscanthus (Petersen et al. 2002), Brassica (Möllers et al. 1994) and tobacco (Takashima et al. 1995). Colchicine can affect not only the percentage of doubling but also the whole androgenetic process. In Brassica, the application of colchicine to isolated microspore cultures resulted in a high embryo induction rate and almost synchronized embryogenesis (Möllers et al. 1994; Zaki and Dickinson 1995; Zhao et al. 1996a, b; Zhou et al. 2002a, b). Studies performed in tobacco and maize indicated that the optimal concentration for embryogenesis had no effect on chromosome doubling while optimal concentration for doubling had negative effects on plant production (Eady et al. 1995; Saisingtong et al. 1996). In bread wheat, application of colchicine during the first hours of anther culture produced contradictory results regarding embryogenesis and percentages of green plants (Barnabás et al. 1991; Navarro-Alvarez et al. 1994; Redha et al. 1998a, b; Zamani et al. 2000, 2003). Only the study from Hansen and Andersen (1998) reported the effect of colchicine on isolated microspore culture in wheat.

The application of a stress pretreatment is necessary for efficient induction of microspore embryogenesis in cereals. Sugar starvation by placing anthers on a medium with mannitol as the carbohydrate source is one the most commonly used stress pretreatments. This pretreatment has provided consistently high chromosome doubling rates in barley (Kasha et al. 2001; Shim et al. 2006) and wheat (Hu and Kasha 1997). In wheat, a stress pretreatment that delayed nuclear division and retained microspores at the uninucleate stage produced more green plants than pretreatments in which microspore division occurred (Hu and Kasha 1999). There is only one report in maize in which colchicine was applied during a cold stress pretreatment (Antoine-Michard and Beckert 1997). In that study, colchicine had no effect on percentage of doubling but significantly increased the number of fertile DH plants.

The aim of this work was to study the effect of colchicine on chromosome doubling and on the androgenic response when applied not only during the first hours of anther and microspore culture, but also during mannitol stress pretreatment in bread wheat. 


\section{MATERIALS AND METHODS}

\section{Plant material}

Spring wheat cvs. Chris, Pavon, Caramba and the doubled haploid line DH24033 were used as donor plants for isolated microspore and anther culture. Chris is a model cultivar for microspore embryogenesis, Pavon is a medium-high responding cultivar, whereas Caramba and DH24033 are low responding. The DH line was chosen because of its low percentage of spontaneous chromosome doubling.

Seeds of donor plants were sown in a paper-pot of $3 \mathrm{~cm}$ in diameter with a mixture of peat, vermiculite and sand (1:1:1). Plants were vernalized for 5 weeks in a growth chamber at $4^{\circ} \mathrm{C}$, under an $8 \mathrm{~h}$ photoperiod. Plants were transplanted to $15 \mathrm{~cm}$ diameter pots with the above soil mixture and cultivated in a growth chamber at $12^{\circ} \mathrm{C}$ with a $12 \mathrm{~h}$ photoperiod. After 5 weeks, the temperature was increased to $21 / 18^{\circ} \mathrm{C}$ and the photoperiod lengthened to $16 \mathrm{~h}$. Relative humidity was kept at $70-80 \%$. Fertilization of the plants was performed as described by Cistué et al. (2006).

\section{Anther and microspore culture}

\section{$\underline{\text { Microspore developmental stage assessment }}$}

For every genotype and batch of plants, four spikes were chosen in order to associate their morphology to the developmental stage of the microspores. One or two anthers were taken from the central flower and squashed in $127.5 \mathrm{~g}^{-1}$ mannitol. A drop of $4^{\prime}$, 6'-diamidino-2-phenylindole (DAPI) stock solution (4 $\mu \mathrm{g} \mu \mathrm{l}^{-1}$ with $0.01 \%$ Tween 20 ) was added (Vergne et al. 1987) and incubation was performed until nuclei were visible under a UV lamp in an epifluorescent microscope (Nikon Eclipse T300).

\section{$\underline{\text { Stress pretreatment }}$}

Anthers containing the majority of microspores at the mid- to late-uninucleate stage for anther culture or at late-uninucleate to early-binucleate stages for microspore culture 
were excised from the flower and plated in $127.5 \mathrm{~g} \mathrm{l}^{-1}$ mannitol, $5.9 \mathrm{~g} \mathrm{l}^{-1} \mathrm{CaCl}_{2}$ plus FHG macronutrients (Hunter 1988) solidified with $8 \mathrm{~g}^{-1}$ Sea Plaque agarose.

\section{$\underline{\text { Ovary preconditioned medium }}$}

Ovaries from flowers containing microspores at the late binucleate or trinucleate stages were excised and used for preconditioning MMS3 medium (MS medium modified by $\mathrm{Hu}$ and Kasha 1997), containing $62 \mathrm{~g} \mathrm{l}^{-1}$ maltose, $1 \mathrm{mg}^{-1}$ 2,4-dichlorophenoxyacetic acid (2,4-D) and $1 \mathrm{mg} \mathrm{l}^{-1}$ benzyladenine (BA) (MS3M). This medium was supplemented with $200 \mathrm{~g} \mathrm{l}^{-1}$ (MS3MF200) or $300 \mathrm{~g}^{-1}$ Ficoll 400 (MS3MF300) for anther and microspore culture, respectively. Medium was preconditioned for 5 days at $25^{\circ} \mathrm{C}$ with 10 ovaries per $1.5 \mathrm{ml}$ of culture media in $3 \mathrm{~cm}$ Petri plates.

\section{Microspore isolation and culture}

After 5 days of pretreatment, anthers were harvested in $54.7 \mathrm{~g}^{-1}$ mannitol and microspores were released using a glass rod homogeneizer. The isolation procedure was performed including viable microspore enrichment by centrifugation on a maltose band, as described by Castillo et al. (2000). Around 50 spikes were used for each isolation. The total number of microspores was estimated using a haemocytometer (Neubauer) and the percentage of viable microspores was determined by the fluorescein diacetate technique (Widholm 1972). After counting, we centrifuged the microspore suspension ( $5 \mathrm{~min}, 110 \mathrm{~g}$ ), removed the mannitol solution with at Pasteur pipet and resuspended the pellet in MS3M medium. Microspores were inoculated at a final density of $80-$ $100 \times 10^{3}$ microspores $/ \mathrm{ml}$ in $3 \mathrm{~cm}$ Petri plates containing ovary preconditioned MS3MF300. After 8-10 days of culture, an equal amount of similar fresh medium was added to each plate.

\section{$\underline{\text { Anther culture }}$}

After mannitol pretreatment, anthers were inoculated in $3 \mathrm{~cm}$ plates containing $1.5 \mathrm{ml}$ ovary preconditioned MS3MF200 medium. Around 40 anthers were cultured per plate. Ten to 12 days after culture, an equal amount of MS3MF300 was added to each Petri dish. 


\section{$\underline{\text { Plant regeneration and soil transfer }}$}

Embryos that developed after 30-60 days of culture were transferred to J25-8 medium (Jensen 1983) for regeneration. Embryos were kept in the dark at $25^{\circ} \mathrm{C}$ for 2 days and transferred to the light. After 20-30 days, plants were counted and transferred to Magenta boxes containing similar medium plus NAA $\left(2 \mathrm{mg} \mathrm{l}^{-1}\right)$ for root development. Plants were vernalized for 5 weeks at $4^{\circ} \mathrm{C}$ and $8 \mathrm{~h}$ photoperiod before transfer to soil. Afterwards, plants were transferred to the greenhouse for seed production. Plants with seed set greater than $90 \%$ were considered doubled haploids.

\section{Colchicine application}

\section{Colchicine application during mannitol pretreatment}

The three anthers of each flower were randomly distributed to three pretreatment media containing different concentrations of colchicine: 0 (Control), 150 (Col 150) and $300 \mathrm{mg} \mathrm{l}^{-1}$ (Col 300), so that each pretreatment medium contained one anther from every flower. After 5 days of pretreatment, microspores were isolated and cultivated as previously described.

Colchicine application during the first hours of microspore and anther culture

In microspore culture, four treatments were used: one untreated control in which microspores were cultivated as previously described; two treatments in liquid MS3M with colchicine (150 and $300 \mathrm{mg} \mathrm{l}^{-1}$ ); and one control treatment in liquid MS3M without colchicine. In anther culture, three treatments were applied: 0, 150 and $300 \mathrm{mg}^{-1}$ colchicine in liquid MS3M medium. In both types of culture, colchicine treatments were conducted in $3 \mathrm{~cm}$ plates containing $1.5 \mathrm{ml}$ medium for $48 \mathrm{~h}$. After this time, treated microspores were transferred to a $15 \mathrm{ml}$ centrifuge tube and washed in liquid MS3M by centrifugation ( $5 \mathrm{~min}, 110 \mathrm{~g}$ ). Treated anthers were washed with $2 \mathrm{ml}$ liquid MS3M. Afterwards, microspore and anther cultures were performed as previously described. 


\section{$\underline{\text { Ploidy analysis }}$}

Ploidy was estimated by flow cytometry after transferring plants to soil. Young leaves were chopped in $2 \mathrm{ml}$ Cystain UV ploidy solution (Partec) and filtered through a $30 \mu \mathrm{m}$ nylon filter. Samples were analyzed in PA or PAS cytometer (Partec). Leaves from young seedlings were used as control. At least 50 plants from each treatment were analyzed, unless the number of green plants was lower.

\section{Data analysis}

For microspore cultures, each microspore isolation was considered a replicate. Four replicates from different batches of plants were used for studying the effect of colchicine application during pretreatment or culture. Anther culture experiments consisted of ten replicates of approx. 40 anthers per treatment and genotype. The following variables were recorded: number of embryos (nEmb), number of green plants (nGP), and total plants, all per 100 anthers, and percentage of doubling expressed as number of doubled haploids per 100 analyzed plants (pDH). Percentage of regeneration (number of regenerated plants per 100 embryos; pReg), percentage of green plants (number of green plants per 100 total plants; pGP) and number of green DH plants per 100 anthers (nGDH) were calculated.

All experiments were established in a completely randomized design. Standard SAS/STAT procedures were used for statistical analysis (SAS 1988). ANOVA was conducted for each genotype separately, using the GLM (Generalized Linear Model) procedure for all the variables, except for $\mathrm{pDH}$ which was analyzed using the $\chi^{2}$-test. Mean separation was tested by the Duncan method $(\alpha \leq 0.05)$.

\section{RESULTS}

\section{Colchicine application during mannitol pretreatment}

In the model cv. Chris, either of the two colchicine concentrations used did not significantly affect any of the variables related to plant production: $n E m b, n G P, p R e g$ or pGP (Table 1). Among these variables, only nGP was significantly increased in the 
medium-high responding cv. Pavon, from 7 in control to 11 with $300 \mathrm{mg}^{-1}$ colchicine. In Caramba, similar percentages of regeneration and green plants were obtained in control and $300 \mathrm{mg}^{-1}$ colchicine cultures, although a detrimental effect was observed with $150 \mathrm{mg}^{-1}$. Similar numbers of embryos and green plants were obtained in control and colchicine treated cultures of Caramba.

Regarding percentage of chromosome doubling (pDH), the $150 \mathrm{mg} \mathrm{l}^{-1}$ colchicine treatment did not differ significantly from controls of any cultivar (Table 1). However, the $300 \mathrm{mg} \mathrm{l}^{-1}$ treatment was detrimental in $\mathrm{cv}$. Pavon, stimulatory in cv. Caramba and ineffective in cv. Chris.

The number of green DH plants, which expresses the index of success of the procedure, was unaffected by colchicine in Chris and Caramba. However, this variable was significantly improved in Pavon, from 4 in control to 6 with $300 \mathrm{mg} \mathrm{l}^{-1}$ colchicine, mainly due to the greater number of green plants produced.

\section{Colchicine application during the first hours of microspore and anther culture}

\section{Effect of the application method in microspore culture}

To study the effect of the application method itself, we compared untreated microspores (Control) and microspores treated with $0 \mathrm{mg}^{-1}$ colchicine (Col 0) (Table 2). There was a negative effect of the treatment procedure in cvs. Chris and Pavon. The percentage of green plants in cv. Pavon was reduced significantly from $66 \%$ to $18 \%$. This led to a decrease in the nGP, with a two-fold and a four-fold decrease in Chris and Pavon, respectively. However, in the DH24033 line, the method of application enhanced nEmb, without affecting pReg or pGP, and thus resulted in a four-fold increase in the number of green plants.

The percentage of spontaneous doubling was significantly increased by the application method in cv. Pavon (from 35\% to 50\%) and DH24033 (from 22\% to 34\%) (Table 2). The number of green DH plants was also affected by the application method. A twofold and a five-fold decrease in this variable were observed in cvs. Chris and Pavon, respectively, mainly due to the lower number of green plants produced in the treated control. Conversely, the number of green DH plants from DH24033 was increased from 
0.3 in control cultures to 1.2 in treated control, because of the greater number of embryos in this treatment.

\section{Effect of the colchicine application during the first hours of microspore culture}

The effect of colchicine at 0 (Col 0), 150 (Col 150) and $300 \mathrm{mg} \mathrm{l}^{-1}$ (Col 300) in the induction medium on green plant production varied with the genotype (Table 2). In Pavon, a 2-fold increase in $\mathrm{nEmb}$ was observed with both concentrations compared with $0 \mathrm{mg}^{-1}$. Percentage of green plants was also significantly increased up to 2-fold with $300 \mathrm{mg}^{-1}$ in Pavon. As a consequence, the number of green plants increased from 1 with $0 \mathrm{mg}^{-1}$ to 3 with $150 \mathrm{mg}^{-1}$. No significant differences were observed in $\mathrm{nEmb}$, pReg, nGP and pGP in cv. Chris and DH24033.

The percentage of chromosome doubling was significantly increased with $300 \mathrm{mg}^{-1}$ colchicine compared with $0 \mathrm{mg}^{-1}$ in the three genotypes used. The greatest effect was observed for DH24033 and cv. Pavon with a $118 \%$ and $76 \%$ increase in the percentage of doubling, respectively.

Similar numbers of green DH plants in cv. Chris were obtained with $0 \mathrm{mg}^{-1}$ and the two colchicine concentrations used. In Pavon, the number of green DH plants increased up to 8 times with $300 \mathrm{mg} \mathrm{l}^{-1}$, due not only to the greater percentage of chromosome doubling but also to the greater number of embryos and percentage of green plants obtained compared with $0 \mathrm{mg} \mathrm{l}^{-1}$. In DH24033 this variable increased, although not significantly, from 1.2 with $0 \mathrm{mg} \mathrm{l}^{-1}$ to 5.6 with $300 \mathrm{mg}^{-1}$ colchicine.

\section{Effect of the colchicine application during the first hours of anther culture}

Colchicine did not significantly affect the number of responding anthers, embryos and green plants, or percentages of regeneration and green plants in either of the two cultivars used (Table 3), although a slight decrease in the number of embryos occurred in Caramba with $150 \mathrm{mg}^{-1}$.

Chromosome doubling significantly increased in colchicine treatments in both cultivars (Table 3). Similar percentages of spontaneous doubling were obtained in the control treatment for both cultivars (33\%), and it improved significantly up to $50 \%$ in Pavon and $58 \%$ in Caramba, after treatment with $300 \mathrm{mg}^{-1}$ of colchicine. As a consequence, 
the number of green DH plants also increased significantly (about 50\%) in both cultivars when $300 \mathrm{mg} \mathrm{l}^{-1}$ colchicine was incorporated during the first hours in the induction medium.

Comparison of ploidy and plant fertility measured by percent seed set was performed. The correlation between ploidy determined by flow cytometry and fertility of plants was high $\left(r^{2}=87.8, P=0.01\right)$. The percentage of aneuploid plants that produced few seeds was $0.1 \%$. Seed set from DH plants from colchicine treated cultures was similar to that of control plants.

\section{DISCUSSION}

This is the first report of the influence of colchicine incorporated into the mannitol stress pretreatment on the androgenetic process. Mannitol pretreatments at $28^{\circ} \mathrm{C}$ to wheat uninucleate microspores have delayed nuclear division and produced more green plants (Hu and Kasha 1999). Since colchicine inhibits spindle formation, and thus could have accumulated microspores at mitosis, an increase in the number of green plants might have been expected by the application of colchicine during the pretreatment. However, in this study, a significant increase in the number of green plants was observed with $300 \mathrm{mg} \mathrm{l}^{-1}$ only for cv. Pavon. Incorporation of colchicine during cold pretreatment in maize improved anther response and embryogenesis, without affecting percentage of doubling (Antoine-Michard and Beckert 1997). On the contrary, in this study, a significant increase in percentage of doubling was observed in cv. Caramba with $300 \mathrm{mg} \mathrm{l}^{-1}$ whereas this concentration produced a significant decrease in cv. Pavon. These results show that the colchicine effect on green plant production and percentage of doubling was genotype dependent.

When colchicine was applied during the first hours of culture, its effects on number of embryos and on percentage of green plants depended on the genotype and on the culture method. In microspore culture, colchicine improved these two variables only in cultivar Pavon, but had no influence in either of the two cultivars used in anther culture. An increase in embryogenesis was also reported in microspore culture of Brassica (Zhou et al. 2002a, b), whereas no effect was observed in wheat microspore culture (Hansen and Andersen 1998). In wheat anther culture, enhancement of embryogenesis (Barnabás 
et al. 1991) and toxic effects (Navarro-Alvaréz et al. 1994; Redha et al. 1998a, b) have been described. The different genotypes used in these studies could explain these contradictory results. Also, toxics effects have been reported in F1 durum $\times$ wheat hybrids (Tersi et al. 2006). Stimulation of embryogenesis has also been reported in anther culture of some genotypes of maize (Obert and Barnabás 2004) and rice (Alemanno and Guiderdoni 1994). Different actions of colchicine have been proposed that could explain the positive effects on embryogenesis, as an increase of symmetrical divisions (Szakacs and Barnabás 1995), the depression in the synthesis of pollen specific tubulins (Cleveland et al. 1983; Carpenter et al. 1992), and cytoskeletal restructuration (Shariatpanahi et al. 2006).

Negative effects on percentage of green plants in microspore culture (Hansen and Andersen 1998) and negative and positive effects in anther culture (Barnabás et al. 2001; Ouyang et al. 1994; Redha et al. 1998a, b; Zamani et al. 2000) have been previously described in wheat. It has been suggested that colchicine could cause a reduction of chloroplast DNA abnormalities (Aubry et al. 1989) or a selective elimination of microspores having abnormalities (Barnabás et al. 1991), increasing the percentage of green plants.

In this study, colchicine application during the first hours of microspore or anther cultures resulted in higher rates of chromosome doubling in all the genotypes. These results are in accordance with those previously reported in anther culture (Barnabás et al. 1991; Navarro-Alvarez et al. 1994; Redha et al. 1998a, b; Zamani et al. 2000) and microspore culture of wheat (Hansen and Andersen 1998), as in other species, such as maize (Saisingtong et al. 1996; Barnabás et al. 1999), triticale (Arzani and Darvey 2001) and Brassica (Möllers et al. 1994; Hansen and Andersen 1996; Zhou et al. 2002a, b). The doubling rate increased more significantly in cv. Pavon and DH24033 than in cv. Chris. Genotypic dependence has also been described previously in wheat (Barnabás 2003; Zamani et al. 2003) and Brassica (Möllers et al. 1994; Weber et al. 2005). The differences among genotypes in their responses to colchicine might be related to the kinetics of mitotic division in culture (Zaki and Dickinson 1991).

A compromise should be adopted for the selection of concentration and treatment duration. Colchicine concentrations above $120 \mathrm{mg} / 1$ for $48 \mathrm{~h}$ in microspore culture (Hansen and Andersen 1998) and 100-200 $\mathrm{mg}^{-1}$ for $72 \mathrm{~h}$ in anther culture (Navarro- 
Alvarez et al. 1994; Redha et al.1998a) have been reported to increase percentage of doubling but also reduced embryogenesis and/or green plant regeneration in wheat. However, the concentrations of colchicine applied in the present study allowed us to increase percentage of doubling and still no deleterious effects, or even positive effects on androgenic response were produced. This suggests that higher concentration of colchicine could further improve DH plant production.

We observed a lower increase in the percentage of chromosome doubling in anther culture than in microspore culture of $\mathrm{cv}$. Pavon with $300 \mathrm{mg} \mathrm{l}^{-1}$ colchicine $(51 \%$ and $76 \%$, respectively). Also, positive effects produced by colchicine on embryogenesis and percentage of green plants in microspore culture of Pavon were not observed in anther culture. This variation of colchicine effects between microspore and anther culture could be due to the fact that different microspore stages were used. Also, the anther wall could be acting as a filter (Pulido et al. 2005), avoiding complete absorption of colchicine. If so, longer treatments or higher concentrations of colchicine would be necessary in anther than in microspore culture to produce the same effect.

The negative effect of the application method itself in cvs. Chris and Pavon could be due to the initial culture of microspores in liquid medium and subsequent manipulation of microspores during washing. Similar effects have been described in wheat (Hansen and Andersen 1998) and in Brassica (Hansen and Andersen 1996; Zhao et al. 1996b). However, in this study around a 3-fold increase in the number of embryos was produced by the application method in the DH line. This positive effect could be explained by the high percentage of mortality of the microspores during the first 2 days of culture in this cultivar. Washing microspores could be helpful for the elimination of toxic compounds released by dead or deteriorating microspores into the culture medium, thus increasing the number of embryos. These results agree with those reported in Brassica by Fletcher et al. (1988) and Zhou et al. (2002b) who found that a change of the induction medium 15-24 h after microspore isolation could be essential to allow normal embryo initiation and development.

The incorporation of colchicine during the first hours of anther and microspore culture increased the number of green DH plants compared with treated controls in two cultivars and the DH24033 whereas colchicine application during the stress pretreatment only increased the number of green DH plants in one of the two cultivars 
used. From these results we conclude that colchicine application during the first hours of culture is more effective than during the stress pretreatment. Colchicine was successfully used in both anther and microspore culture, in cultivars with medium or low rates of doubling. These results encourage the introduction of this methodology into wheat breeding programs. Further improvements could be achieved by optimization of the application method in microspore culture and by the application of longer treatments in anther culture.

Acknowledgements MS was the recipient of a fellowship from the Ministerio de Educación y Ciencia of the Spanish Government. We thank the Instituto de Agrobiotecnología y Recursos Naturales (UPNA-CSIC) for the use of the PA flow cytometer. The research was supported by Proyects from the Plan Nacional de Recursos y Tecnologías Agroalimentarias AGL2002-04139-C02-02 and AGL2005-07195-C0201 .

\section{REFERENCES}

Alemanno L, Guiderdoni E (1994) Increased doubled haploid plant regeneration from rice (Oryza sativa L.) anthers cultured on colchicine supplemented media. Plant Cell Rep 13:432-436

Antoine-Michard S, Beckert M (1997) Spontaneous versus colchicine-induced chromosome doubling in maize anther culture. Plant Cell Tiss Org Cult 48:203-207

Arzani A, Darvey NL (2001) The effect of colchicine on triticale anther-derived plants: Microspore pre-treatment and haploid-plant treatment using a hydroponic recovery system. Euphytica 122:235-241

Aubry CJ, De Buyser J, Hartmann C, Henry Y, Rode A (1989) Changes in molecular organization of the mitochondrial genome in albino tissue cultures derived from wheat pollen embryos and in plants regenerated from theses cultures. Plant Sci $65: 103-110$

Barnabás B (2003) Protocol for producing doubled haploid plants from anther culture of wheat (Triticum aestivum L). In: Malupszynski M, Kasha K, Foster B, Szarejko I (eds) Doubled Haploid Production in Crop Plants. A Manual. FAO/IAEA Division, Wien, pp65-70 
Barceló P, Cabrera A, Hagel C, Lörz H (1994) Production of doubled haploid plants from tritordeum anther culture. Theor Appl Genet 87:741-745

Barnabás B, Obert B, Kovács G. (1999) Colchicine, an efficient genome-doubling agent for maize (Zea mays L) microspores cultured in anthero. Plant Cell Rep 18:858-862

Barnabás B, Pfahler PL, Kovács G (1991) Direct effect of colchicine on the microspore embryogenesis to produce dihaploid plants in wheat Triticum aestivum L. Theor Appl Genet 81:675-678

Barnabás B, Szakacs E, Karsai I, and Bedo Z (2001) In vitro androgenesis of wheat: from fundamentals to practical application. Euphytica 119:211-216

Bell GDH (1950) Investigations in the Triticineae. I. Colchicine techniques for chromosome doubling in interespecific and intergeneric hybridization. J Agric Sci 40:9-20

Carpenter JL, Ploense SE, Snustad DP, Silflow CD (1992) Preferential expression of an alpha-tubulin gene of Arabidopsis in pollen. Plant Cell 4:557-571

Castillo AM, Vallés MP and Cistué L (2000) Comparison of anther and isolated microspore cultures in barley. Effects of culture density and regeneration medium. Euphytica 113:1-8

Cistué L, Soriano M, Castillo AM, Vallés MP, Sanz JM, Echavarri B (2006) Production of doubled haploid in durum wheat (Triticum turgidum L.) through isolated microspore culture. Plant Cell Rep 25:257-264

Chen ZZ, Snyder S, Fan ZG, Loh WH (1994) Efficient production of doubled haploid plants through chromosome doubling of isolated microspores in Brassica napus. Plant Breed 113: 217-221

Cleveland DW, Pittenger MF, Feramisco JR (1983) Elevation of tubulin levels by microinjection suppresses new tubulin synthesis. Nature 30:738-740

Eady C, Lindsey K, Twell D (1995) The significance of microspore division and division symmetry for vegetative cell specific transcription and generative cell differentiation. Plant Cell 7:64-74

Fletcher R, Coventry J, Kott LS (1988) Doubled haploid technology for spring and winter Brassica napus (revised edition). OAC Publications. University of Guelph, Guelph, Ontario, Canada, pp 42

Hansen, NJP, Andersen, SB (1996) In vitro chromosome doubling potential of colchicine, oryzalin, trifluralin, and APM in Brassica napus microspore culture Eupytica 88: 159-164 
Hansen NJP, Andersen SB (1998) In vitro chromosome doubling with colchicine during microspore culture in wheat (Triticum aestivum L.) Eupytica 102:101-108

Hassawi DS, Liang GH (1991) Antimitotic agents: Effects on double haploid production in wheat. Crop Sci 31:723-726

$\mathrm{Hu}$ T, Kasha KJ (1997) Improvement of isolated microspore culture in wheat (Triticum aestivum L.) through ovary co-culture. Plant Cell Rep 16:520-525

$\mathrm{Hu}$ T, Kasha KJ (1999) A cytological study of pretreatmetns used to improve isolated microspore cultures of wheat (Triticum aestivum L.) cv. Chris. Genome 42:432-441

Hunter CP (1988) C.P. Plant regeneration from microspores of barley, Hordeum vulgare L. Ph.D. Thesis. Wye College, Univ London, London

Jensen CJ (1974) Chromosome Doubling Techniques. In: Kasha KJ (ed) Haploids in Higher Plants. Advances and Potential. Proceedings of the First International Symposium, Guelph, Canada, pp153-190

Jensen CJ (1983) Producing haploid plants by chromosome elimination. In: Cell and Tissue Culture Techniques for Cereal Crop Improvements. Science Press, Beijing, China, pp55-79

Kasha KJ, Hu TC, Oro R, Simion E, Shim YS (2001) Nuclear fusion leads to chromosome doubling during mannitol pretreatment of barley (Hordeum vulgare L.) microspores. J Exp Bot 52:1227-1238

Laurie DA, Bennett MD (1987) The effect of crossability loci $K r 1$ and $K r 2$ on fertilization frequency in haploid wheat $\times$ maize crosses. Theor Appl Genet 73:403409

Levan A (1938) The effect of colchicine on root mitosis in Allium. Hereditas 24:471486

Mentewab A, and. Sarrafi A, (1997) Androgenic ability and chromosome doubling by different colchicine treatments in anther culture of hexaploid wheat genotypes. Cereal Res. Commun 25: 897-903

Möllers C, Iqbal MCM, Röbbelen G (1994) Efficient production of doubled haploid Brassica napus plants by colchicine treatment of microspores. Euphytica 75:95-104.

Navarro-Alvarez W, Baenziger PS, Eskridge KM, Hugo M, Gustafson VD (1994) Addition of colchicine to wheat anther culture media to increase doubled haploid plant production. Plant Breed 112:192-198. 
Obert B, Barnabás B (2004) Colchicine induced embryogenesis in maize. Plant Cell Tiss Org Cult 77:283-285.

Ouyang JW, Zhou SM, Jia SE (1983) The response of anther culture to culture temperature in Triticum aestivum. Theor Appl Genet 66:101-109

Ouyang JW, Lian H, Jia SE, Zhang C, Zhao TH, He LZ, Jia X (1994) Studies on chromosome doubling of wheat pollen plants. Plant Science 98(2):209-214

Petersen KK, Hagberg P, Kristiansen K (2002) In vitro chromosome doubling of Miscanthus sinensis. Plant Breed 121:445-450

Pulido A, Bakos F, Castillo A, Valles MP, Barnabás B and Olmedilla A (2005) Cytological and ultrastructural changes induced in anther and isolated-microspore cultures in barley: Fe deposits in isolated-microspore cultures. J Struct Biol 149:170-181

Redha A, Attia T, Büter B, Saisingtong S, Stamp P, Schmid JE (1998a) Improved production of doubled haploids by colchicine application to wheat (Triticum aestivum L.) anther culture. Plant Cell Rep 17:974-979

Redha A, Attia T, Büter B, Stamp P, Schmid JE (1998b) Single and combined effects of colchicine, L-proline and post-inoculation low temperature on anther culture of wheat, Triticum aestivum L. Plant Breed 117:335-340

Saisingtong S, Schmid JE, Stamp P, Büter B.(1996) Colchicine-mediated chromosome doubling during anther culture of maize (Zea mays L.) Theor Appl Genet 92:10171023

SAS (1988) SAS/STAT User'Guide, Release 6.03 edn. SAS Institute Inc Cary; NC, USA

Shariatpanahi ME, Bal U, Heberle-Bors E, Touraev A (2006) Stresses applied for the re-programming of plant microspores towards in vitro embryogenesis. Physiol Plant 127:519-534

Shim YS, Kasha KJ, Simion E, Letarte J (2006) The relationship between induction of embryogenesis and chromosome doubling in microspore cultures. Protoplasma 228:79-86

Stober A, Hess D (1997) Spike pre-treatment, anther culture conditions, and anther culture response of 17 German varieties of spring wheat (Triticum aestivum L.). Plant Breed 116: 443-447. 
Szakacs E, Barnabás B (1995) The effect of colchicine treatment on microspore division and microspore-derived embryo differentiation in wheat (Triticum aestivum L.) anther culture. Euphytica 83:209-213

Takasima S, Hasegava H, Nakamura A (1995) A simple method for chromosome doubling in tobacco anther culture - direct application of colchicine to anthers before culture. Breed Sci 45:107-110

Tersi M, Xynias IN, Gouli-Vavdinoudi E, Roupakias DG (2006) Anther culture response of F-1 durum $\mathrm{X}$ bread wheat hybrids after colchicine application. Plant Breed 125: 457-460.

Vergne P, Delvallee I, Dumas C (1987) Rapid assessment of microspore and pollen development stage in wheat and maize using dapi and membrane permeabilization. Stain Technol 62: 299-304

Weber S, Ünker F, Friedt W (2005) Improved doubled haploid production protocol for Brassica napus using microspore colchicine treatment in vitro and ploidy determination by flow cytometry. Plant Breed 124:511-513

Widholm JM (1972) Use of fluorescein diacetate and phenosafranine for determining viability of cultured plant cells. Stain Technol 47:189-194

Zaki M, Dickinson H (1991) Microspore derived embryos in Brassica: the significance of division symmetry on pollen mitosis I to embryogenic development. Sex Plant Reprod 4:48-55

Zaki M, Dickinson H (1995) Modification of cell development in vitro: The effect of colchicine on anther and isolated microspore culture in Brassica napus. Plant Cell Tiss Org Cult 40:255-270

Zamani I, Gouli-Vavdinoudi E, Kovacs G, Xynias I, Roupakias D, Barnabás B (2003) Effect of parental genotypes and colchicine treatment on the androgenic response of wheat $\mathrm{F}_{1}$ hybrids Plant Breed 122, 314-317.

Zamani I, Kovács G, Gouli-Vavdinoudi E, Roupakias DG, Barnabás B (2000) Regeneration of fertile doubled haploid plants from colchicine-supplemented media in wheat anther culture. Plant Breed 119:461-465

Zhao JP, Simmonds DH, Newcomb W (1996a) High frequency production of doubled haploid plants of Brassica napus cv. Topas derived from colchicine-induced microspore embryogenesis without heat shock. Plant Cell Rep 15:668-671 
Zhao JP, Simmonds DH, Newcomb W (1996b) Induction of embryogenesis with colchicine instead of heat in microspores of Brassica napus L. cv. Topas. Planta 198:433-439

Zhou WJ, Tang GX, Hagberg P (2002a) Efficient production of doubled haploid plants by immediate colchicine treatment of isolated microspores in winter Brassica napus. Plant Growth Regul 37:185-192

Zhou WJ, Hagberg P, Tang GX (2002b) Increasing embryogenesis and doubling efficiency by immediate colchicine treatment of isolated microspores in spring Brassica napus. Euphytica 128:27-34 
Table 1 Effect of the incorporation of colchicine during the mannitol stress pretreatment applied to anthers, on microspore culture response of three cultivars of bread wheat

\begin{tabular}{llcccccc}
\hline Cultivar & $\begin{array}{l}\text { Treatment } \\
\left(\mathrm{mgl}^{-1}\right)\end{array}$ & nEmb $^{*}$ & pReg & pGP & nGP* & pDH & nGDH $^{*}$ \\
\hline Chris & Col 0 & $90 \mathrm{a}^{+}$ & $69 \mathrm{a}$ & $98 \mathrm{a}$ & $61 \mathrm{a}$ & $70 \mathrm{a}$ & $42 \mathrm{a}$ \\
& Col 150 & $123 \mathrm{a}$ & $65 \mathrm{a}$ & $99 \mathrm{a}$ & $79 \mathrm{a}$ & $60 \mathrm{a}$ & $50 \mathrm{a}$ \\
& Col 300 & $96 \mathrm{a}$ & $70 \mathrm{a}$ & $98 \mathrm{a}$ & $66 \mathrm{a}$ & $67 \mathrm{a}$ & $44 \mathrm{a}$ \\
\multirow{5}{*}{ Pavon } & Col 0 & $34 \mathrm{a}$ & $54 \mathrm{a}$ & $37 \mathrm{a}$ & $7 \mathrm{~b}$ & $66 \mathrm{a}$ & $4 \mathrm{~b}$ \\
& Col 150 & $46 \mathrm{a}$ & $49 \mathrm{a}$ & $37 \mathrm{a}$ & $8 \mathrm{ab}$ & $72 \mathrm{a}$ & $5 \mathrm{ab}$ \\
& Col 300 & $55 \mathrm{a}$ & $49 \mathrm{a}$ & $43 \mathrm{a}$ & $11 \mathrm{a}$ & $56 \mathrm{~b}$ & $6 \mathrm{a}$ \\
& Col 0 & $21 \mathrm{a}$ & $56 \mathrm{a}$ & $50 \mathrm{a}$ & $6 \mathrm{a}$ & $55 \mathrm{~b}$ & $4 \mathrm{a}$ \\
& Col 150 & $27 \mathrm{a}$ & $49 \mathrm{~b}$ & $28 \mathrm{~b}$ & $4 \mathrm{a}$ & $60 \mathrm{ab}$ & $3 \mathrm{a}$ \\
& Col 300 & $21 \mathrm{a}$ & $52 \mathrm{ab}$ & $45 \mathrm{a}$ & $5 \mathrm{a}$ & $69 \mathrm{a}$ & $3 \mathrm{a}$ \\
\hline
\end{tabular}

* Values are based on 100 anthers

${ }^{+}$Values followed by the same letter within cultivars and columns are not significantly different $(P<0.05)$ 
Table 2 Effect of the incorporation of colchicine during the first $48 \mathrm{~h}$ of microspore culture of three genotypes of bread wheat

\begin{tabular}{llcccccc}
\hline Genotype & $\begin{array}{l}\text { Treatment } \\
\left(\mathrm{mgl}^{-1}\right)\end{array}$ & nEmb & pReg & pGP & nGP & pDH & nGDH \\
\hline Chris & Control & $58 \mathrm{a}^{+}$ & $41 \mathrm{a}$ & $98 \mathrm{a}$ & $23 \mathrm{a}$ & $62 \mathrm{~b}$ & $14.3 \mathrm{a}$ \\
& Col 0 & $44 \mathrm{a}$ & $29 \mathrm{a}$ & $99 \mathrm{a}$ & $13 \mathrm{ab}$ & $53 \mathrm{~b}$ & $6.7 \mathrm{a}$ \\
& Col 150 & $33 \mathrm{a}$ & $37 \mathrm{a}$ & $100 \mathrm{a}$ & $12 \mathrm{ab}$ & $55 \mathrm{~b}$ & $6.6 \mathrm{a}$ \\
& Col 300 & $37 \mathrm{a}$ & $26 \mathrm{a}$ & $99 \mathrm{a}$ & $9 \mathrm{~b}$ & $77 \mathrm{a}$ & $7.2 \mathrm{a}$ \\
& Control & $13 \mathrm{ab}$ & $47 \mathrm{a}$ & $66 \mathrm{a}$ & $4 \mathrm{a}$ & $35 \mathrm{c}$ & $1.4 \mathrm{a}$ \\
& Col 0 & $9 \mathrm{~b}$ & $37 \mathrm{a}$ & $18 \mathrm{~b}$ & $1 \mathrm{a}$ & $50 \mathrm{~b}$ & $0.3 \mathrm{~b}$ \\
& Col 150 & $21 \mathrm{a}$ & $55 \mathrm{a}$ & $30 \mathrm{ab}$ & $3 \mathrm{a}$ & $57 \mathrm{~b}$ & $1.9 \mathrm{a}$ \\
& Col 300 & $21 \mathrm{a}$ & $36 \mathrm{a}$ & $38 \mathrm{a}$ & $3 \mathrm{a}$ & $88 \mathrm{a}$ & $2.5 \mathrm{a}$ \\
& Control & $9 \mathrm{a}$ & $17 \mathrm{a}$ & $87 \mathrm{a}$ & $1 \mathrm{a}$ & $22 \mathrm{c}$ & $0.3 \mathrm{~b}$ \\
& Col 0 & $28 \mathrm{a}$ & $14 \mathrm{a}$ & $93 \mathrm{a}$ & $4 \mathrm{a}$ & $34 \mathrm{~b}$ & $1.2 \mathrm{ab}$ \\
& Col 150 & $34 \mathrm{a}$ & $32 \mathrm{a}$ & $94 \mathrm{a}$ & $10 \mathrm{a}$ & $60 \mathrm{a}$ & $6.2 \mathrm{a}$ \\
& Col 300 & $32 \mathrm{a}$ & $27 \mathrm{a}$ & $90 \mathrm{a}$ & $8 \mathrm{a}$ & $73 \mathrm{a}$ & $5.6 \mathrm{a}$ \\
\hline
\end{tabular}

* Values are based on 100 anthers

${ }^{+}$Values followed by the same letter within genotypes and columns are not significantly different $(P<0.05)$ 
Table 3 Effect of the incorporation of colchicine during the first $48 \mathrm{~h}$ of anther culture of two cultivars of bread wheat

\begin{tabular}{lllllllll}
\hline Cultivar & $\begin{array}{l}\text { Treatment } \\
\left(\mathrm{mgl}^{-1}\right)\end{array}$ & $\begin{array}{c}\text { Resp. } \\
\text { Ant(\%) }\end{array}$ & nEmb & pReg & pGP & nGP & pDH & nGDH $^{*}$ \\
\hline Pavon & Col 0 & $44 \mathrm{a}^{+}$ & $419 \mathrm{a}$ & $50 \mathrm{a}$ & $62 \mathrm{a}$ & $117 \mathrm{a}$ & $33 \mathrm{~b}$ & $38 \mathrm{~b}$ \\
& Col 150 & $43 \mathrm{a}$ & $361 \mathrm{a}$ & $51 \mathrm{a}$ & $66 \mathrm{a}$ & $144 \mathrm{a}$ & $35 \mathrm{~b}$ & $46 \mathrm{~b}$ \\
& Col 300 & $43 \mathrm{a}$ & $376 \mathrm{a}$ & $48 \mathrm{a}$ & $60 \mathrm{a}$ & $129 \mathrm{a}$ & $50 \mathrm{a}$ & $60 \mathrm{a}$ \\
Caramba & Col 0 & $23 \mathrm{a}$ & $178 \mathrm{a}$ & $49 \mathrm{a}$ & $61 \mathrm{a}$ & $68 \mathrm{a}$ & $33 \mathrm{~b}$ & $23 \mathrm{~b}$ \\
& Col 150 & $21 \mathrm{a}$ & $103 \mathrm{a}$ & $46 \mathrm{a}$ & $61 \mathrm{a}$ & $32 \mathrm{a}$ & $54 \mathrm{a}$ & $15 \mathrm{~b}$ \\
& Col 300 & $22 \mathrm{a}$ & $159 \mathrm{a}$ & $58 \mathrm{a}$ & $64 \mathrm{a}$ & $70 \mathrm{a}$ & $58 \mathrm{a}$ & $35 \mathrm{a}$
\end{tabular}

* Values are based on 100 anthers

${ }^{+}$Values followed by the same letter within cultivar and columns are not significantly different $(P<0.05)$ 